\title{
Article \\ Physical Activity of the Right- and Left-Footed Professional Soccer Players from Symmetrical Defensive Positions
}

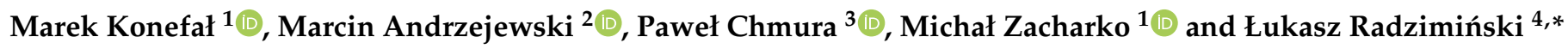 \\ 1 Department of Biological and Motor Sport Bases, University School of Physical Education, \\ 51-612 Wroclaw, Poland; marek.konefal@awf.wroc.pl (M.K.); michal.zacharko@awf.wroc.pl (M.Z.) \\ 2 Department of Recreation, Poznan University of Physical Education, 61-871 Poznan, Poland; \\ andrzejewski@awf.poznan.pl \\ 3 Department of Team Games, University School of Physical Education, 51-612 Wroclaw, Poland; \\ pawel.chmura@awf.wroc.pl \\ 4 Department of Physiology, Gdansk University of Physical Education and Sport, 80-336 Gdansk, Poland \\ * Correspondence: lukasz.radziminski@awf.gda.pl
}

Citation: Konefał, M.; Andrzejewski, M.; Chmura, P.; Zacharko, M.; Radzimiński, Ł. Physical Activity of the Right- and Left-Footed Professional Soccer Players from Symmetrical Defensive Positions. Symmetry 2021, 13, 1551. https:/ / doi.org/10.3390/sym13091551

Academic Editor: Luca Paolo Ardigo

Received: 29 July 2021

Accepted: 19 August 2021

Published: 24 August 2021

Publisher's Note: MDPI stays neutral with regard to jurisdictional claims in published maps and institutional affiliations.

Copyright: (C) 2021 by the authors Licensee MDPI, Basel, Switzerland. This article is an open access article distributed under the terms and conditions of the Creative Commons Attribution (CC BY) license (https:/ / creativecommons.org/licenses/by/ $4.0 /)$.

\begin{abstract}
The main purpose of this study was to compare the physical match performance of right- and left-footed external defenders during official matches of Polish Ekstraklasa. The sample comprised 991 individual observations from 296 matches during the 2019/2020 season. Variables such as total distance, distance covered in high-speed running and sprinting, and number of highintensity runs were analysed. Additionally, the data were presented in relation to match duration and effective playing time. Right external defenders (right ED) covered significantly longer total distance $(p<0.001,1.5 \%)$, high-speed running distance $(p<0.001,5.6 \%)$ and sprinting distance $(p<0.001$, $11.4 \%$ ) compared to left external defenders (left ED). The number of high-intensity runs was greater for right RD as well ( $p<0.001,6.4 \%$ ). Physical match activity for left ED who are left-footed was significantly higher $(p<0.001)$ in comparison with right-footed left ED. The number of offensive actions played on the right side of the pitch was significantly $(p<0.001)$ higher than those performed on the left side. Players whose dominant foot is in accordance with the side of the pitch cover longer distances during the match. Moreover, the number of offensive actions played through the wings could affect the physical performance of external defenders.
\end{abstract}

Keywords: human movement; time-motion analysis; football; dominant foot; symmetry; full-backs

\section{Introduction}

Soccer is considered as the most popular sport in the world. During a $90 \mathrm{~min}$ match, players perform different physical activities such as accelerations, decelerations, turns, jumps, sprints and many others [1,2]. Recording the quantitative parameters is possible due to advanced technologies such as the Global Positioning System (GPS) or video tracking systems which, in combination with human intelligence and experience, allow us to analyse the motor activity of players playing in different positions in the leagues from different countries [3-5]. This is very important because the evaluation of match performance is a crucial task for coaches, which enables them to develop the competition efficiency of individual players, tactical formations and the team as a whole. Therefore, systematic monitoring of official matches is indispensable for improving a team's performance.

Physical match performance has been previously described in the scientific literature [6,7]. It is widely known that short, high-intensity activities (e.g., high-intensity running distance, sprinting distance or number of high-intensity runs) are crucial variables in determining the final result of the game [8]. These actions usually allow players to obtain better positions for taking shots or key passes [9-11]. During the match $12 \%$ of the total distance travelled is performed at sprint intensity, with short efforts in time and distance [12]. Among all the positions on the pitch, external defenders (ED) are distinguished in terms 
of speed activities. Most analyses indicate that the high-intensity match performance of EDs (distance covered in high-intensity running and sprinting) is greater in comparison to other positions [13-17]. However, a relatively low number of authors investigated the behaviour of EDs during the match [18-20]. These authors found that the technical match performance (actions with the ball) of EDs is also unique. They lose the ball less often than other players, their passing accuracy is higher and their time on the ball is shorter. These activities are usually connected with simultaneously realising offensive and defensive tactical tasks [21,22]. It shows that the team strategy should consider position-specific levels of physical fitness and technical skills $[2,23]$.

The level of soccer-specific skills are often determined by a player's individual potential. One of the crucial attributes is laterality. Carey et al. [24] demonstrated a strong inclination among players to use the dominant foot during all soccer activities. This behaviour was most common during set pieces, dribbling and passes (85\%). Players used their non-dominant foot only when under high pressure from an opponent. Moreover, Granero-Gil et al. [25] found significant differences in centripetal force between the players with dominant right and left feet.

Scientists from different areas have previously highlighted the importance of factors influencing human motion. Such researchers could provide numerous solutions which simplify function in various spheres of life [26,27], including professional sport. Since the beginning of the twenty-first century, physical match performance has been investigated by numerous authors. When assessing running match performance, factors such as playing position, match outcome or match location should be taken into account $[28,29]$. Some authors [30] suggested that assessing the match demands including the ball-out-of-play time, otherwise the impact of high-intensity play on game performance may be underestimated. Therefore, reporting the physical performance, not only according to full match duration but also in relation to effective playing time $\left(E_{t}\right)$, seems to be appropriate. All of these studies provided practical applications for sport scientists and soccer coaches that could be useful in preventing the undesirable decline in match performance.

The match activity of players from the symmetrical position should be evaluated with reference to the tactical system of the team. Systems based on four defenders seem to be the most appropriate for this type of analysis [31]. The right and left ED can then be clearly distinguished. During the analysed season, 2019-2020, fifteen of a total of sixteen teams of the Polish Ekstraklasa filled these criteria (played in the system with four defenders) and performed their matches with four defenders.

The main purpose of this research was to compare running performance of right- and left-footed professional soccer players from symmetric positions during official matches.

\section{Materials and Methods}

\subsection{Participants}

A total of 296 official Polish Ekstraklasa matches from season 2019/2020 were analysed. The sample comprised 991 individual match observations of external defenders (ED): 490 right ED (448 right-footed, 23 left-footed. 19 both-footed) and 501 left EDs (102 rightfooted, 378 left-footed, 21 both-footed). 56 players completed a $90 \mathrm{~min}$ performance as a right ED and 57 players as a left ED. Only matches performed by the teams that played with four defenders were taken into account. All data were anonymized in accordance with the Declaration of Helsinki to ensure the anonymity of the participants. This study was approved by the Senate Research Ethical Committee of University School of Physical Education in Wroclaw (agreement number: 12/2021).

\subsection{Procedures}

This observational study investigated the potential differences in match physical performance between right and left external defenders. The physical activity data were collected using the previously-validated [32] TRACAB system (ChyronHego, NY, USA). This system consists of two multicamera units (each comprising three HD-SDI cameras 
with a resolution of $1920 \times 1080$ pixels) located on both sides of the half line. The sampling frequency of this system was $25 \mathrm{~Hz}$. Variables such as total distance (TD), distance covered in high-speed running (HSR; 19.8-25.1 $\left.\mathrm{km} \cdot \mathrm{h}^{-1}\right)$ and in sprinting $\left(>25.2 \mathrm{~km} \cdot \mathrm{h}^{-1}\right)$, and number of high-intensity runs (NHIR) were analysed. NHIR were defined as a sum of runs with a speed higher than $19.8 \mathrm{~km} \cdot \mathrm{h}^{-1}$ [33]. Additionally, the data were presented in relation to match duration (relative TD, relative HSR and relative sprinting distance) and in relation to effective playing time. These indicators were calculated by dividing the running performance variable (e.g., TD) by the number of minutes of the match or the number of $E_{t}$ minutes. $E_{t}$ was defined as game duration after removing the time taken up by all stoppages, such as injuries, substitutions, VAR interventions, etc. [28]. In other words, this is the total time during which the ball is in play. The number of offensive actions was collected from the previously described InStat video analysis system $[34,35]$. Moreover, the reliability of this tracking system has been previously established by passing the official FIFA (Fédération Internationale de Football Association) test protocol for Electronic \& Performance Tracking Systems (EPTS). The dominating foot of the participants was determined using the player's profiles on the website www.transfermarkt.pl and verified by two experienced coaches working in Ekstraklasa clubs.

\subsection{Statistical Analysis}

All data were presented as mean \pm standard deviation. The normality of the distribution of the data sets were assessed using the Shapiro-Wilk test. Comparisons between right and left external defenders were calculated using the $t$-test for independent samples for most variables. When a lack of normal distribution was detected, the Mann-Whitney $\mathrm{U}$ test was applied. Moreover, Cohen's $d$ effect sizes (ES) were determined according to Cohen [36]. ES were classified as trivial $(d<0.2)$, small $(0.2 \leq d<0.5)$, medium $(0.5 \leq d<0.8)$ and large $(d>0.8)$. Significance was established at the $p \leq 0.05$ level. All analyses were performed using Statistica software version 13.0 (TIBCO Software Inc, 2017).

\section{Results}

As presented in Table 1 and Figure 1, right ED covered significantly longer TD $(p<0.001$, $1.5 \%)$, HSR distance $(p<0.001,5.6 \%)$ and sprinting distance $(p<0.001,11.4 \%)$. Moreover, NHIR in right EDs was significantly higher $(p<0.001,6.4 \%)$. Similarly, the relative values of TD, HSR and sprinting were significantly shorter for left EDs $(p<0.001,1.6 \%, 5.7 \%$ and $11.2 \%$ respectively). The analysis of data in relation to effective playing time also indicated significant differences. TD/ $E_{t}, H S R / E_{t}$ and sprinting $/ E_{t}$ were significantly longer for right EDs when compared with left ED. Additionally, the analysis of right and left ED match activity, according to their dominant foot, exhibited that physical match activity for left EDs who are left-footed was significantly higher $(p<0.001)$ in comparison with right-footed left EDs (Table 2). However, this effect was not observed for right EDs. Finally, the number of offensive actions played on the right side of the pitch was significantly $(p<0.001)$ higher than those performed on the left side ( $29.9 \pm 7.16$ vs. $28.7 \pm 6.58$ respectively, Figure 2$)$.

Table 1. Physical performance of right and left external defenders during official matches.

\begin{tabular}{|c|c|c|c|c|c|}
\hline & $\begin{array}{l}\text { Right ED } \\
(n=490)\end{array}$ & $\begin{array}{c}\text { Left ED } \\
(n=501)\end{array}$ & $p$ & ES & $\Delta(\%)$ \\
\hline $\mathrm{TD}[\mathrm{m}]$ & $10,733 \pm 628.2$ & $10,570 \pm 558.3$ & 0.000018 & 0.26 & 1.52 \\
\hline NHIR & $65.6 \pm 15.0$ & $61.4 \pm 12.6$ & 0.000002 & 0.30 & 6.40 \\
\hline Relative TD [m/min] & $111.1 \pm 6.76$ & $109.3 \pm 5.98$ & 0.000019 & 0.26 & 1.62 \\
\hline Relative HSR [m/min] & $7.70 \pm 1.90$ & $7.26 \pm 1.55$ & 0.000071 & 0.25 & 5.71 \\
\hline Relative Sprinting [m/min] & $2.41 \pm 1.09$ & $2.14 \pm 0.96$ & 0.000021 & 0.27 & 11.20 \\
\hline $\mathrm{TD} / \mathrm{E}_{\mathrm{t}}[\mathrm{m} / \mathrm{min}]$ & $193.0 \pm 18.94$ & $189.8 \pm 17.71$ & 0.006364 & 0.17 & 1.66 \\
\hline $\mathrm{HSR} / \mathrm{E}_{\mathrm{t}}[\mathrm{m} / \mathrm{min}]$ & $13.37 \pm 3.42$ & $12.60 \pm 2.85$ & 0.000135 & 0.24 & 5.76 \\
\hline Sprinting $/ \mathrm{E}_{\mathrm{t}}[\mathrm{m} / \mathrm{min}]$ & $4.19 \pm 1.89$ & $3.71 \pm 1.69$ & 0.000022 & 0.27 & 11.46 \\
\hline
\end{tabular}




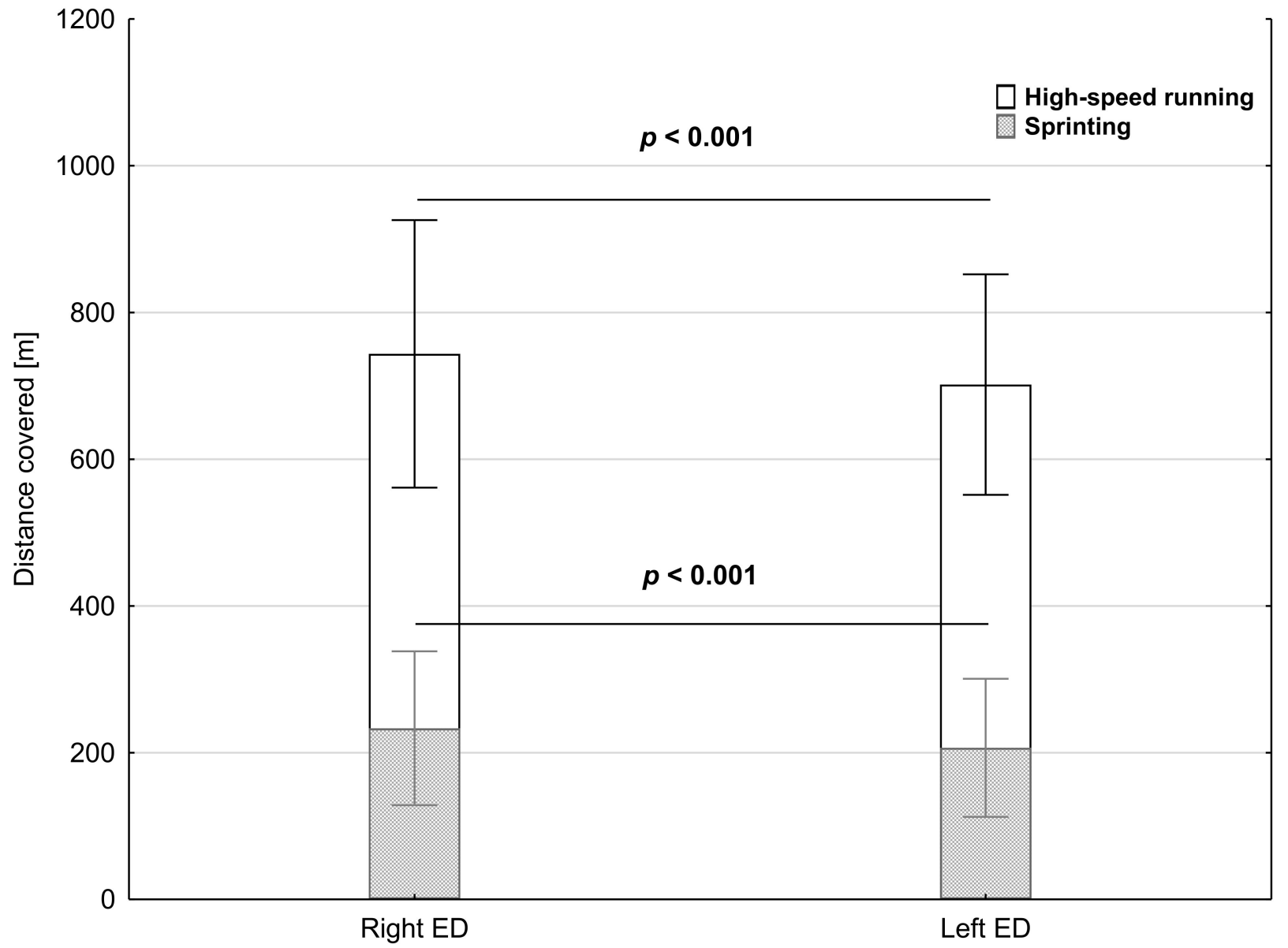

Figure 1. Distance covered in HSR and sprinting (mean and SD) by right and left external defenders from Polish Ekstraklasa.

Table 2. Comparison of right- and left-footed external defenders.

\begin{tabular}{ccccc}
\hline & \multicolumn{2}{c}{ Right ED } & \multicolumn{2}{c}{ Left ED } \\
\hline & $\begin{array}{c}\text { Right-Footed } \\
(\boldsymbol{n}=\mathbf{4 4 8 )}\end{array}$ & $\begin{array}{c}\text { Left-Footed } \\
(\boldsymbol{n = 2 3 )}\end{array}$ & $\begin{array}{c}\text { Right-Footed } \\
(\boldsymbol{n = 1 0 2 )}\end{array}$ & $\begin{array}{c}\text { Left-Footed } \\
(\boldsymbol{n}=\mathbf{3 7 8})\end{array}$ \\
\hline TD [m] & $10,728 \pm 635.9$ & $10,631 \pm 591.1$ & $10,317 \pm 544.3$ & $10,612 \pm 540.9^{*}$ \\
HSR [m] & $742.2 \pm 182.4$ & $747.5 \pm 216.1$ & $635.2 \pm 130.2$ & $718.2 \pm 152.0^{*}$ \\
Sprinting [m] & $235.0 \pm 106.4$ & $242.7 \pm 88.8$ & $174.6 \pm 97.0$ & $218.8 \pm 91.9^{*}$ \\
NHIR & $65.4 \pm 15.1$ & $67.1 \pm 16.4$ & $55.3 \pm 12.0$ & $63.2 \pm 12.4^{*}$ \\
\hline
\end{tabular}

${ }^{*}$ significantly different from right-footed at $p<0.001$. 


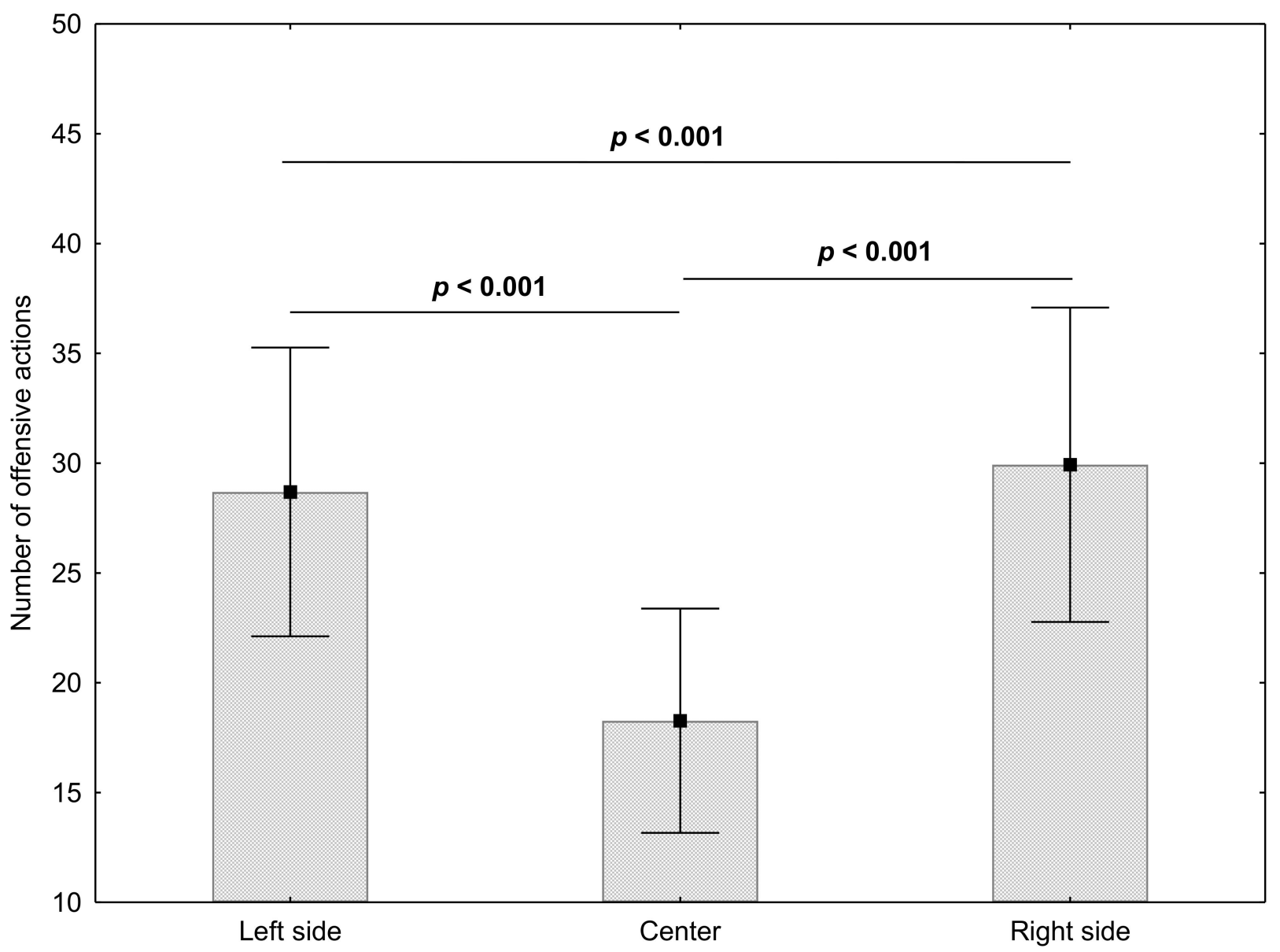

Figure 2. Distribution of the offensive actions regarding the sides of the pitch.

\section{Discussion}

This study aimed to compare the physical performance of right- and left-footed professional soccer players during official matches, representing symmetrical defensive positions. To the best of our knowledge, this is the first study comparing the time-motion data of players from the right and left sides of the pitch with reference to the dominant foot. The main finding of our research was that right EDs covered significantly longer TD distance, distance covered in HSR and in sprinting than left external defenders. Moreover, the NHIR was significantly higher for right EDs as well. Concerning dominant foot, the detailed analysis of left EDs exhibited that the match activity of left-footed players was significantly higher in comparison with right-footed defenders.

Greater values of physical match performance variables in right EDs seem to be slightly surprising. Theoretically, the performance of players from symmetrical positions should be very similar. Numerous authors analysed the match running performance of professional soccer players according to their playing position [37-39]. Konefał et al. [40] reported that, in Bundesliga, TD covered by right fullbacks was longer than in left fullbacks (10.60 km vs. $10.48 \mathrm{~km}$, respectively). Although these results are in line with our research, the difference in high-intensity activities were not detected in German Bundesliga. Both distance covered with speeds above $24 \mathrm{~km} \cdot \mathrm{h}^{-1}$ and number of sprints (runs with a speed $>22.68 \mathrm{~km} \cdot \mathrm{h}^{-1}$ ) were very similar for players from both sides of the defensive formation.

As mentioned above, data showed that high-intensity activities of left and right external defenders from Polish Ekstraklasa differ from the analyses of the German Bundesliga; thus, analysing running performance in relation to $E_{t}$ could provide additional information. Recently, there have been an increasing number of studies considering physical match performance with reference to $E_{t}[30,41,42]$. Such analyses were reported to be even more 
accurate in providing the high-intensity match demands data than whole match variables. This could be explained by the fact that, during the ball-out-of-play periods, players are usually moving back to their positions without the pressure of time. Therefore, the intensity of these movements is very low. In our study, the differences in running performance between right and left EDs were presented in a traditional way and in relation to both total match duration and to $\mathrm{E}_{\mathrm{t}}$. Comparison between the positions exhibited significant differences for all these variables. Regardless of the form of presented data (total, in relation to match duration or $\mathrm{E}_{\mathrm{t}}$ ), the range of the differences between right and left ED was very similar in TD (1.5-1.7\%), HSR (5.6-5.8\%) and sprinting (11.2-11.5\%).

Although both-footed players could more easily reach the highest level of competence, most of the players have one dominant foot. Previous research established that soccer players prefer to use their dominant foot in most situations across the game [24]. The non-dominant foot is usually used only under high pressure from the opponent. The comparison of time-motion analysis of EDs with reference to dominant foot indicated that left-footed left EDs covered significantly longer TD, HSR distance, sprinting distance and NHIR. Due to the very small sample size of left-footed players $(n=23)$, this effect was not reported for right ED. However, over $95 \%$ of right ED observations were performed by right-footed players, while only $79 \%$ of left ED were left-footed. When a player's dominant foot is consistent with the side on the pitch, they often show a natural tendency to run with the ball towards the end line (goal line). In contrast, players with their dominant foot opposite from the side of the defence often decide either to run with the ball to the middle zone of the pitch or pass the ball back. Thus, the distance covered by these players could possibly be shorter. These differences in preferred dribbling direction may result in the asymmetry of centripetal force generated for the performance of the action [25]. In addition, it should be noted that match running performance could possibly be dependent on factors such as trained schemes of offensive actions (e.g., taking part in every offensive action or only during these actions, which are played on a chosen side of the pitch) or tactical tasks during the defensive phase of the game [31,43].

The largest offensive activity on the right side may have contributed to the greater physical match performance of right EDs. Additionally, this situation could be related to the large number of right-footed players playing as right EDs (over 96\%). The InStat video analysis system provided numerous data about technical and tactical match performance. One such variable is the number of offensive actions performed by the team. These actions are divided into three zones: left wing, centre of the pitch and right wing. In Polish Ekstraklasa, during the season 2019/2020, the largest number of offensive actions were performed through the right wing (39\%) then through the left wing $(37 \%)$, while only $24 \%$ offensive actions were played through the centre zones of the pitch.

Some limitations of this study are worth mentioning. The presented research was conducted only during one season in one specific league (Polish Ekstraklasa). Therefore, the data obtained should be considered with some caution. Furthermore, the contextual variables influencing match running performance were not taken into account during statistical analyses. Finally, the individual potential of the players (e.g., level of physical fitness or anthropological dimensions) that could affect the physical match performance was not included in our research. Future research from this scientific area should consider performance of the players from other symmetrical positions (e.g., wingers). Such analysis could provide extensive practical information for game analytics.

\section{Conclusions}

In this study, the comparison of physical match performance of right and left EDs was investigated. Players from the right side of the defence covered significantly longer TD, HSR distance, sprint distance and NHIR. Similarly, the relative values of these variables were higher for right ED. This surprising observation could be explained in two ways. The greater number of offensive actions played through the right wing could contribute to the higher physical performance of right ED. Furthermore, the larger number of right-footed 
right EDs than left-footed left EDs could result in covering a longer distance during the match. If the dominant leg is in line with the side of the pitch, players take part in offensive actions more willingly. Thus, coaches and sport scientists should take into account whether the dominant foot of the ED is consistent with the side of the pitch when assessing the physical performance of the players. Moreover, training processes should consider playing position, laterality and field zone to individualize players' workload.

Author Contributions: Conceptualization, M.K. and Ł.R.; methodology, M.K., M.A., P.C. and Ł.R.; software, M.K. and Ł.R.; validation, M.K., P.C., M.Z. and Ł.R.; formal analysis, M.K. and Ł.R.; investigation, M.K. and Ł.R.; resources, M.K., M.Z. and Ł.R.; data curation, M.K., M.Z. and Ł.R.; writing-original draft preparation, M.K. and Ł.R.; writing-review and editing, M.K. and Ł.R.; visualization, M.K. and Ł.R.; supervision, M.K., M.A., P.C. and Ł.R.; project administration, M.K. and Ł.R.; funding acquisition, M.K. All authors have read and agreed to the published version of the manuscript.

Funding: This research received no external funding.

Institutional Review Board Statement: This study maintained the anonymity of the players following data protection law. The study was conducted in accordance with the Declaration of Helsinki and approved by the Senate Research Ethical Committee of University School of Physical Education in Wroclaw (agreement number: 12/2021).

Informed Consent Statement: Not applicable.

Data Availability Statement: The data used for this study were acquired from a third-party, https: / / tracabportal.azurewebsites.net/login. The data was provided under scientific cooperation with a football clubs currently appearing in Polish Ekstraklasa. The authors' ethical approval also prevents them from sharing any data in any way that could be re-identified. The metadata would allow someone else to re-identify teams and possibly players. However, access to the data should be possible from the third-party. The data acquired were so-called 'excel dumps' of player statistics per match. Access to the data can be arranged by contacting Match Analysis Hub: info@chyronhego.com.

Conflicts of Interest: The authors declare no conflict of interest.

\section{References}

1. Harper, D.J.; Carling, C.; Kiely, J. High-Intensity Acceleration and Deceleration Demands in Elite Team Sports Competitive Match Play: A Systematic Review and Meta-Analysis of Observational Studies. Sports Med. 2019, 49, 1923-1947. [CrossRef]

2. Stolen, T.; Chamari, K.; Castagna, C.; Wisloff, U. Physiology of Soccer: An Update. Sports Med. 2005, 35, 501-536. [CrossRef]

3. Castellano, J.; Alvarez-Pastor, D.; Bradley, P.S. Evaluation of Research Using Computerised Tracking Systems (Amisco ${ }^{\circledR}$ and Prozone $^{\circledR}$ ) to Analyse Physical Performance in Elite Soccer: A Systematic Review. Sports Med. 2014, 44, 701-712. [CrossRef]

4. Filetti, C.; Ruscello, B.; D'Ottavio, S.; Fanelli, V. A Study of Relationships among Technical, Tactical, Physical Parameters and Final Outcomes in Elite Soccer Matches as Analyzed by a Semiautomatic Video Tracking System. Percept. Mot. Ski. 2017, 124, 601-620. [CrossRef]

5. Liu, H.; Hopkins, W.; Gómez, A.M.; Molinuevo, S.J. Inter-operator reliability of live football match statistics from OPTA Sportsdata. Int. J. Perform. Anal. Sport 2013, 13, 803-821. [CrossRef]

6. Konefał, M.; Chmura, P.; Tessitore, A.; Melcer, T.; Kowalczuk, E.; Chmura, J.; Andrzejewski, M. The Impact of Match Location and Players' Physical and Technical Activities on Winning in the German Bundesliga. Front. Psychol. 2020, 11, 1748. [CrossRef] [PubMed]

7. Sarmento, H.; Marcelino, R.; Anguera, M.T.; Campaniço, J.; Matos, N.; Leitão, J. Match analysis in football: A systematic review. J. Sports Sci. 2014, 32, 1831-1843. [CrossRef] [PubMed]

8. Andrzejewski, M.; Konefał, M.; Chmura, P.; Kowalczuk, E.; Chmura, J. Match outcome and distances covered at various speeds in match play by elite German soccer players. Int. J. Perform. Anal. Sport 2016, 16, 817-828. [CrossRef]

9. Dalen, T.; Øverås, Ø.; van den Tillaar, R.; Welde, B.; von Heimburg, E.D. Influence of different soccer-specific maximal actions on physiological, perceptual and accelerometer measurement loads. Open Access J. Sports Med. 2018, 9, 107-114. [CrossRef] [PubMed]

10. Loturco, I.; Nimphius, S.; Kobal, R.; Bottino, A.; Zanetti, V.; Pereira, L.A.; Jeffreys, I. Change-of direction deficit in elite young soccer players: The limited relationship between conventional speed and power measures and change-of-direction performance. Ger. J. Exerc. Sport Res. 2018, 48, 228-234. [CrossRef]

11. Mohr, M.; Krustrup, P.; Bangsbo, J. Match performance of high-standard soccer players with special reference to development of fatigue. J. Sports Sci. 2003, 21, 519-528. [CrossRef] [PubMed]

12. Di Salvo, V.; Baron, R.; González-Haro, C.; Gormasz, C.; Pigozzi, F.; Bachl, N. Sprinting analysis of elite soccer players during European Champions League and UEFA Cup matches. J. Sports Sci. 2010, 28, 1489-1494. [CrossRef] [PubMed] 
13. Aquino, R.; Carling, C.; Vieira, L.H.P.; Martins, G.; Jabor, G.; Machado, J.; Santiago, P.; Garganta, J.; Puggina, E. Influence of Situational Variables, Team Formation, and Playing Position on Match Running Performance and Social Network Analysis in Brazilian Professional Soccer Players. J. Strength Cond. Res. 2020, 34, 808-817. [CrossRef] [PubMed]

14. Barrera, J.; Sarmento, H.; Clemente, F.; Field, A.; Figueiredo, A. The Effect of Contextual Variables on Match Performance across Different Playing Positions in Professional Portuguese Soccer Players. Int. J. Environ. Res. Public Health 2021, 18, 5175. [CrossRef]

15. Rivilla-García, J.; Calvo, L.C.; Jiménez-Rubio, S.; Paredes-Hernández, V.; Muñoz, A.; van den Tillaar, R.; Navandar, A. Characteristics of Very High Intensity Runs of Soccer Players in Relation to Their Playing Position and Playing Half in the 2013-14 Spanish La Liga Season. J. Hum. Kinet. 2019, 66, 213-222. [CrossRef]

16. Andrzejewski, M.; Chmura, P.; Konefał, M.; Kowalczuk, E.; Chmura, J. Match outcome and sprinting activities in match play by elite German soccer players. J. Sports Med. Phys. Fit. 2018, 58, 785-792. [CrossRef]

17. Konefał, M.; Chmura, P.; Kowalczuk, E.; Figueiredo, A.J.; Sarmento, H.; Rokita, A.; Chmura, J.; Andrzejewski, M. Modeling of relationships between physical and technical activities and match outcome in elite German soccer players. J. Sports Med. Phys. Fit. 2019, 59, 752-759. [CrossRef]

18. Bradley, P.S.; Sheldon, W.; Wooster, B.; Olsen, P.; Boanas, P.; Krustrup, P. High-intensity running in English FA Premier League soccer matches. J. Sports Sci. 2009, 27, 159-168. [CrossRef] [PubMed]

19. Carling, C. Analysis of physical activity profiles when running with the ball in a professional soccer team. J. Sports Sci. 2010, 28, 319-326. [CrossRef] [PubMed]

20. Lago-Peñas, C.; Lago-Ballesteros, J. Game Location and Team Quality Effects on Performance Profiles in Professional Soccer. J. Sports Sci. Med. 2011, 10, 465-471.

21. Dellal, A.; Wong, D.P.; Moalla, W.; Chamari, K. Physical and technical activity of soccer players in the French First League-With special reference to their playing position. Int. Sport Med. J. 2010, 11, 278-290.

22. Dellal, A.; Chamari, K.; Wong, D.P.; Ahmaidi, S.; Keller, D.; de Barros, R.M.L.; Bisciotti, G.N.; Carling, C. Comparison of physical and technical performance in European soccer match-play: FA Premier League and La Liga. Eur. J. Sport Sci. 2011, 11, 51-59. [CrossRef]

23. Carling, C.; Dupont, G. Are declines in physical performance associated with a reduction in skill-related performance during professional soccer match-play? J. Sports Sci. 2011, 29, 63-71. [CrossRef]

24. Carey, D.P.; Smith, D.; Martin, D.; Smith, G.; Skriver, J.; Rutland, A.; Shepherd, J.W. The bi-pedal ape: Plasticity and asymmetry in footedness. Cortex 2009, 45, 650-661. [CrossRef] [PubMed]

25. Granero-Gil, P.; Gómez-Carmona, C.D.; Bastida-Castillo, A.; Rojas-Valverde, D.; De La Cruz, E.; Pino-Ortega, J. Influence of playing position and laterality in centripetal force and changes of direction in elite soccer players. PLoS ONE 2020, 15, e0232123. [CrossRef]

26. Wieczorek, B.; Kukla, M. Effects of the performance parameters of a wheelchair on the changes in the position of the centre of gravity of the human body in dynamic condition. PLoS ONE 2019, 14, e226013. [CrossRef]

27. Wieczorek, B.; Warguła, L.; Rybarczyk, D. Impact of a Hybrid Assisted Wheelchair Propulsion System on Motion Kinematics during Climbing up a Slope. Appl. Sci. 2020, 10, 1025. [CrossRef]

28. Castellano, J.; Blanco-Villaseñor, A.; Álvarez, D. Contextual Variables and Time-Motion Analysis in Soccer. Int. J. Sports Med. 2011, 32, 415-421. [CrossRef] [PubMed]

29. Chmura, P.; Konefał, M.; Chmura, J.; Kowalczuk, E.; Zając, T.; Rokita, A.; Andrzejewski, M. Match outcome and running performance in different intensity ranges among elite soccer players. Biol. Sport 2018, 35, 197-203. [CrossRef] [PubMed]

30. Wass, J.; Mernagh, D.; Pollard, B.; Stewart, P.; Fox, W.; Parmar, N.; Jones, B.; Kilduff, L.; Turner, A.N. A comparison of match demands using ball-in-play vs. whole match data in elite male youth soccer players. Sci. Med. Footb. 2019, 4, 142-147. [CrossRef]

31. Bradley, P.S.; Carling, C.; Archer, D.; Roberts, J.; Dodds, A.; Di Mascio, M.; Paul, D.; Diaz, A.G.; Peart, D.; Krustrup, P. The effect of playing formation on high-intensity running and technical profiles in English FA Premier League soccer matches. J. Sports Sci. 2011, 29, 821-830. [CrossRef] [PubMed]

32. Linke, D.; Link, D.; Lames, M. Football-specific validity of TRACAB's optical video tracking systems. PLoS ONE 2020, 15, e0230179. [CrossRef]

33. Rampinini, E.; Coutts, A.J.; Castagna, C.; Sassi, R.; Impellizzeri, F.M. Variation in Top Level Soccer Match Performance. Int. J. Sports Med. 2007, 28, 1018-1024. [CrossRef] [PubMed]

34. Kubayi, A.; Toriola, A. Match Performance Indicators that Discriminated Between Winning, Drawing and Losing Teams in the 2017 AFCON Soccer Championship. J. Hum. Kinet. 2020, 72, 215-221. [CrossRef]

35. Modric, T.; Versic, S.; Sekulic, D.; Liposek, S. Analysis of the Association between Running Performance and Game Performance Indicators in Professional Soccer Players. Int. J. Environ. Res. Public Health 2019, 16, 4032. [CrossRef]

36. Cohen, J. Statistical Power Analysis for the Behavioural Sciences, 2nd ed.; Lawrence Erlbaum: Mahwah, NJ, USA, 1988.

37. Baptista, I.; Johansen, D.; Seabra, A.; Pettersen, S.A. Position specific player load during match-play in a professional football club. PLoS ONE 2018, 13, e0198115. [CrossRef]

38. Chmura, P.; Liu, H.; Andrzejewski, M.; Chmura, J.; Kowalczuk, E.; Rokita, A.; Konefał, M. Is there meaningful influence from situational and environmental factors on the physical and technical activity of elite football players? Evidence from the data of 5 consecutive seasons of the German Bundesliga. PLoS ONE 2021, 16, e0247771. [CrossRef] 
39. Redwood-Brown, A.J.; O'Donoghue, P.G.; Nevill, A.M.; Saward, C.; Sunderland, C. Effects of playing position, pitch location, opposition ability and team ability on the technical performance of elite soccer players in different score line states. PLoS ONE 2019, 14, e0211707. [CrossRef]

40. Konefał, M.; Chmura, P.; Zając, T.; Chmura, J.; Kowalczuk, E.; Andrzejewski, M. A New Approach to the Analysis of PitchPositions in Professional Soccer. J. Hum. Kinet. 2019, 66, 143-153. [CrossRef]

41. Mernagh, D.; Weldon, A.; Wass, J.; Phillips, J.; Parmar, N.; Waldron, M.; Turner, A. A Comparison of Match Demands Using Ball-in-Play versus Whole Match Data in Professional Soccer Players of the English Championship. Sports 2021, 9, 76. [CrossRef]

42. Riboli, A.; Semeria, M.; Coratella, G.; Esposito, F. Effect of formation, ball in play and ball possession on peak demands in elite soccer. Biol. Sport 2021, 38, 195-205. [CrossRef] [PubMed]

43. Andrzejewski, M.; Chmura, J.; Chmura, P.; Konefał, M.; Pukszta, D. Analysis of Match Performance of Full-backs from Selected European Soccer Leagues. Central Eur. J. Sport Sci. Med. 2015, 11, 45-53. [CrossRef] 